\title{
Outlander: um olhar feminino sobre a sexualidade
}

\section{Outlander: feminine gaze on sexuality}

Carlos Gerbase ${ }^{1}$

1 Pós-doutorado em Cinema pela Université Sorbonne Nouvelle - Paris 3 e doutor em Comunicação Social pela PUCRS. É professor titular no Curso de Produção Audiovisual e no Programa de Pós-Graduação em Comunicação da PUCRS. É cineasta, com sete longas lançados. É autor de quatro obras literárias de ficção e de três obras ensaísticas na área de cinema. E-mail: cgerbase@pucrs.br. 


\section{Resumo}

A partir da releitura do ensaio Prazer visual e cinema narrativo, texto feminista clássico dos anos 1970, de autoria de Laura Mulvey, que acusa o cinema mundial - e em especial o produzido em Hollywood de ser machista e transformar o espectador, independente de gênero, em um voyeur do sexo masculino, discuto neste trabalho as possíveis transformações acontecidas nesse quadro estético nos últimos 40 anos. Os objetos empíricos deste estudo são o romance Outlander, de Diana Gabaldon, e a primeira temporada da série de TV homônima, que estão bem distantes da misoginia apontada por Mulvey. Uma sequência de ações referentes a uma relação sexual, presente tanto no romance quanto na série televisiva, foi analisada detalhadamente, de modo a flagrar novas estratégias narrativas e estéticas da indústria audiovisual contemporânea.

\section{Palavras-chave}

Cinema, feminismo, escopofilia, televisão, indústria audiovisual.

\section{Abstract}

From the rereading of the essay Visual pleasure and narrative cinema, a classic feminist text of the 1970 s by Laura Mulvey, who accuses world cinema - and especially Hollywood cinema - of being sexist and transforming the spectator, regardless of gender, in a male voyeur, we discuss in this work the possible transformations occurred in this aesthetic framework in the last 40 years. The empirical objects of this study are Diana Gabaldon's novel Outlander and the first season of the eponymous TV series, which are far from the misogyny pointed out by Mulvey. A sequence of actions regarding a sexual relationship, present in both the novel and the television series, was analyzed in detail, in order to catch new narrative and aesthetic strategies of the contemporary audiovisual industry.

\section{Keywords}

Cinema, feminism, scopophilia, TV, audiovisual industry. 
A predominância de homens nos postos mais importantes da indústria audiovisual - produção, direção e roteiro - é um dado histórico irrefutável. Desde a sua invenção, no final do século 19, as decisões estéticas do cinema estão, comumente, em mãos masculinas. As relações emocionais e sexuais são um tema constante nos filmes, e suas representações não estão imunes a esse desequilíbrio de gênero, tão comum em inúmeras outras atividades humanas. Hollywood soube, ao longo do tempo, fazer do erotismo um fator de atração de público, e não é surpreendente constatar que, sendo os homens os comandantes do processo de realização dos filmes, esse erotismo esteja baseado num ponto de vista masculino.

Mesmo que haja exceções, esse panorama não se modificou ao longo do tempo. Há menos bons papeis femininos que bons papeis masculinos no cinema narrativo clássico. Há menos enredos baseados em ações de mulheres que enredos centralizados em ações de homens. E, nas cenas de sexo, há muito mais nudez feminina que masculina, o que indica que o corpo da mulher é um objeto para o olhar do homem. O feminismo vem denunciando há décadas essa situação, e alguns textos importantes foram escritos a esse respeito, em especial a partir da década de 1970. Impõe-se a questão: a partir desse protesto, é possível notar algum movimento para um reposicionamento da representação feminina nos filmes e nas séries de TV, que hoje ocupam posição de destaque no mercado? Partindo de um ensaio de Laura Mulvey, de trechos do romance Outlander, de Diana Gabaldon, e da série de TV homônima, tentarei responder a essa pergunta.

\section{Os olhos de Laura Mulvey}

Em Prazer visual e cinema narrativo, texto clássico dos anos 70, a intelectual feminista inglesa Laura Mulvey promove um forte ataque contra certas estruturas narrativas do cinema clássico de Hollywood e suas derivações no resto do mundo. Mulvey acusa os filmes de serem produtos de uma sociedade patriarcal, o que os torna falocentristas: a mulher está a serviço do desejo masculino. Paralelamente, a figura feminina, mesmo desejada, é perigosa, à medida que traz "a ameaça da 
castração, pela ausência real do pênis" (MULVEY, 1983, p. 438). A única maneira de superar essa ameaça é sujeitá-la, independente do tipo de trama ou do gênero do filme, ao poder absoluto do protagonista masculino.

\begin{abstract}
Num mundo governado por um desequilíbrio sexual, o prazer do olhar foi dividido entre ativo/masculino e passivo/feminino. O olhar masculino determinante projeta sua fantasia na figura feminina, estilizada de acordo com essa fantasia. Em seu papel tradicional exibicionista, as mulheres são simultaneamente olhadas e exibidas, tendo sua aparência codificada no sentido de emitir um impacto erótico e visual de modo a que se possa dizer que conota a sua condição de "para ser olhada" (MULVEY, 1983, p. 444).
\end{abstract}

Todo o artigo de Mulvey tem cunho psicanalítico e político. É quase um texto-denúncia, um manifesto feminista contra o cinema hollywoodiano. Isso não impede, de modo algum, que os argumentos de Mulvey sejam coerentes, sustentados por vários exemplos tomados de filmes e ampliados por uma reflexão de base científica (pelo menos para os que consideram a psicanálise uma disciplina científica). Mulvey continua produzindo livros e artigos acadêmicos com temas variados, mas a cada entrevista, mais de 40 anos depois, ainda é obrigada a falar daquele seu ensaio inaugural (eu tinha escrito "seminal", mas desisti, por razões óbvias), que teve grande impacto e lançou a ideia de que os cineastas homens só conseguem ver as mulheres como objetos de seu desejo (e do desejo do espectador), nunca Ihes dando real protagonismo no enredo. E ainda pior: todos os filmes - até os feitos por algumas mulheres - assumem que o desejo do(a) espectador(a) é masculino, o que transforma o público - independente de gênero - num eterno voyeur falocentrado. Na terminologia freudiana, o voyeurismo é a pulsão do prazer de olhar, desenvolvida na infância de forma espontânea, e que pode ou não ser neurótica (FREUD, 2006, p. 180-181).

Mulvey acreditava que, enquanto escrevia, já era possível vislumbrar no horizonte cultural uma outra forma de representação do feminino no cinema. Essa alternativa "cria um espaço para o aparecimento de um outro cinema, radical, tanto num sentido político quanto estético e que desafia os preceitos básicos do cinema dominante" (MULVEY, 1983, p. 439). Infelizmente, Mulvey 
não cita os títulos desses filmes, nem dá pistas de seus realizadores. Já quanto aos filmes falocentristas, a lista é a seguinte: $O$ rio das almas perdidas (de Otto Preminger, com Marilyn Monroe), Uma aventura na Martinica (de Howard Hawks, com Lauren Bacall) e Paraíso infernal (de Howard Hawks, com Rita Hayworth). Alfred Hitchcock e Josef von Sternberg são citados como exemplos de diretores que construíram suas obras a partir de uma narrativa em que "o instinto erótico é concentrado apenas no olhar" (MULVEY, 1983, p. 448). A autora acha que os filmes de Hitchcock são mais sofisticados, enquanto os de Sternberg "fornecem muitos exemplos de pura escopofilia fetichista" (Ibid., p. 448).

Essa última acusação merece uma pequena decodificação, já que são termos psicanalíticos. A escopofilia, ou o prazer de olhar, é, para Freud, uma atitude normal, moldada pela seleção natural: o objeto sexual se torna belo e atrativo aos olhos. Ela se torna uma perversão se, entre três possíveis razões, "suplanta o alvo sexual normal, em vez de ser preparatório a ele" (FREUD, 2006, p. 148). Já o termo fetichismo é utilizado

para designar quer uma atitude da vida sexual normal, que consiste em privilegiar uma parte do corpo do parceiro, quer uma perversão sexual (ou fetichismo patológico), caracterizada pelo fato de uma das partes do corpo (pé, boca, seios, cabelos) ou objetos relacionados com o corpo (sapatos, chapéus, tecidos, etc.) serem tomados como objetos exclusivos de uma excitação (ROUDINESCO; PLON, 1998, p. 235).

Juntando os dois termos, Sternberg seria, segundo Mulvey, um cineasta falocentrista que gosta de um tipo especialmente sofisticado de vouyeurismo. 0 seu objeto de desejo não seria mais a mulher inteira, e sim uma parte de seu corpo, ou algo que veste sobre a pele. Assim, a mulher, antes subjugada, mas ainda visível, agora desaparece completamente.

É interessante verificar como Mulvey incorpora ao seu discurso de crítica cinematográfica o raciocínio e o jargão psicanalíticos, provavelmente influenciada pelo movimento de "retorno a Freud", liderado por Lacan nos anos 1960 e 1970 e que tem Christian Metz (1980) em suas fileiras. Em dado momento, Mulvey escreve que 
"o desejo, nascido com a língua, permite a possibilidade de transcender o instintivo e o imaginário, mas seu ponto de referência retorna continuamente ao momento traumático do nascimento: o complexo de castração" (MULVEY, 1983, p. 443).

Interpretando Mulvey da forma mais restrita possível e evitando os termos "imaginário" e "complexo de castração", por demais escorregadios, o ser humano, embora tenha um componente instintivo (ou "pulsional", conforme Freud preferia) ligado à reprodução sexuada, transcende esse vetor comportamental através do "desejo, nascido com a língua". Se é nascido com a língua, é cultural. Se é cultural, não é animal, posto que só a espécie humana tem linguagem simbólica. Sendo assim, para Mulvey (e para Freud e Lacan), não devemos procurar no trabalho dos cineastas, nem nas personagens que eles constroem nos filmes, reflexos de seus instintos. Seres humanos são animais muito especiais. Enquanto os outros animais são dominados pelos instintos sexuais, ou seja, funcionam no automático, o animal homem tem um "desejo" capaz de ser administrado através de outras construções culturais.

Esse tipo de pensamento predominou nas ciências sociais na maior parte do século 20. A maioria dos sociólogos, antropólogos e psicólogos acreditava que as explicações estavam sempre na cultura, pois a constituição biológica da espécie humana não passava de uma "tábula rasa" para o aprendizado. O cérebro seria alimentado desde o nascimento por componentes culturais e sociais, e os seres humanos "funcionariam" de um modo radicalmente diferente dos outros animais. A psicanálise freudiana reconhece a ideia de "pulsão" (humana), mas evita o termo "instinto" (animal) - posição que é incorporada explicitamente no texto de Mulvey. Não é objetivo deste ensaio contestar essa visão da espécie humana, mas é possível dizer, sem medo de errar, que hoje, em 2017, a ideia da "tábula rasa" é contestada por pesquisas científicas em vários campos, como a neurociência, a genética comportamental e a psicologia evolutiva, em que se destaca o trabalho de Leda Cosmides, Jerome Barkow e John Tooby (1992). A conclusão mais básica dessas pesquisas é que a espécie humana pertence, pelo menos em parte de sua constituição, ao reino animal. Não apenas anatomicamente, 
mas também em seu comportamento (que, em algumas ocasiões, pode ser quase instintivo e automático).

A tese principal de Mulvey, no entanto, continua de pé: independente das origens da distorção (apenas cultural, ou resultante da natureza humana, ou, o que é mais provável, resultado da coevolução de componentes genéticos e culturais), a indústria audiovisual é mesmo pródiga em entregar o protagonismo das ações para as personagens masculinas e usualmente coloca a figura feminina numa posição subalterna, como objeto do desejo masculino. Existem exceções? Com certeza. Elas são muitas e aparentemente se multiplicaram no cinema do século 21. Mas as exceções não escondem nem anulam totalmente as convenções machistas de todo o século 20, que transbordam, ainda que em menor medida, para o nosso século.

Então, seria interessante perguntar: genericamente, será que a indústria audiovisual está mudando? Será que os tais filmes "alternativos e radicais" que Mulvey identificou na década de 1970 alcançaram a necessária relevância estética e social? Não é objetivo deste ensaio responder a essa pergunta de maneira ampla.

Mais pontualmente, será que é possível enxergar num episódio de uma série de TV contemporânea, Outlander, comandada por um homem (o showrunner Ronald D. Moore), baseada em livros escritos por uma mulher (Diana Gabaldon), indícios de uma representação alternativa da figura feminina, conforme a esperança de Mulvey?

É à segunda pergunta que tentarei responder a partir de agora.

\section{Os olhos de Ronald D. Moore}

A série Outlander é resultado de uma associação de produtoras norteamericanas e britânicas. O showrunner, Ronald D. Moore, é norte-americano e sua carreira está muito ligada a séries de ficção-científica, como Star Trek: the next generation e Battlestar galactica, nas quais trabalhava como roteirista. Outlander não é uma obra de ficção-científica, mas está baseada numa das convenções do gênero (a viagem no tempo e os seus paradoxos) e tem elementos de fantasia e misticismo. A estreia de Outlander nos Estados Unidos aconteceu em 2014, na 
forma de uma temporada de 16 episódios. Foi seguida por uma segunda temporada, em 2015, de 13 episódios. Duas novas temporadas estão em produção, sendo que a terceira deve entrar no ar ainda em 2017.

A trama é baseada na extensa série literária Outlander - A viajante do tempo, da escritora norte-americana Diana Gabaldon. São oito volumes até este momento, sendo o primeiro de 1991. Todos são best-sellers internacionais, traduzidos para várias línguas (inclusive o português, no Brasil e em Portugal).

A contracapa do livro registra a seguinte sinopse, que nos parece bastante adequada:

Em 1945, no final da Segunda Guerra Mundial, a enfermeira Claire Randall volta para os braços do marido, com quem desfruta uma segunda lua de mel em Inverness, nas Ilhas Britânicas. Durante a viagem, ela é atraída para um antigo círculo de pedras, no qual testemunha rituais misteriosos. Dias depois, quando resolve retornar ao local, algo inexplicável acontece: de repente se vê no ano de 1743, numa Escócia violenta e dominada por clãs guerreiros. Tão logo percebe que foi arrastada para o passado por forças que não compreende, Claire precisa enfrentar intrigas e perigos que podem ameaçar a sua vida e partir o seu coração. Ao conhecer Jamie, um jovem guerreiro das Terras Altas, sente-se cada vez mais dividida entre a fidelidade ao marido e o desejo pelo escocês. Será ela capaz de resistir a uma paixão arrebatadora e regressar ao presente? (GABALDON, 2014).

O ponto mais interessante das obras (tanto dos romances de Gabaldon, quanto da série de Ronald T. Moore) é, a meu ver, a relação entre a enfermeira Claire, uma mulher culta, urbana e "moderna", que vivia na Inglaterra dos anos 1940, e Jamie, um jovem inteligente, mas de pouca educação formal, que vive no interior da Escócia em 1743. São 200 anos de diferença e, como sabemos, nesse intervalo a cultura humana sofreu grandes mudanças. Em contraste, 200 anos não passam de um instante fugidio na escala evolutiva, de modo que Claire e Jamie, tão diferentes culturalmente, dividem a mesma natureza humana (isso se o leitor acredita que ela existe). Vamos investigar como se dá esse relacionamento, em especial no que se relaciona ao sexo, e em que condições ele foi recriado na linguagem audiovisual. 
Por mais central que seja a figura do showrunner numa série de TV contemporânea (no caso de Outlander, um homem), e por mais significativo que seja o fato da autora da obra original, Diana Gabaldon, e a personagem principal, Claire Randall, serem mulheres, pode ser interessante verificar a presença de outras mulheres na equipe de realização. O IMDB (2017) nos informa que ainda há uma maioria de homens, mas é possível destacar, em relação à primeira temporada, que:

1. a direção é exercida por homens em 12 episódios, enquanto uma mulher, Anna Foerster, dirige 4 (7, 8, 15 e 16);

2. o roteiro, que tem sempre a supervisão (e às vezes a coautoria) de Ronald T. Moore, é escrito por homens em 13 episódios, enquanto Anne Kenney, uma mulher, escreve três (3, 7 e 12);

3. o episódio 7, intitulado O Casamento, em que acontece a primeira relação sexual de Claire Randall e Jamie Fraser, é escrito e dirigido por mulheres. Como veremos a seguir, esse fato não é uma coincidência.

Ronald T. Moore parece disposto a procurar um olhar mais feminino sobre a relação do casal em sua lua de mel. Em entrevista à repórter Maureen Ryan, da revista Variety, Moore conta que evitou ao máximo usar os velhos clichês de cenas de sexo, como velas, uma cortina levada pelo vento, o arco das costas da mulher, uma luz dourada sobre seu corpo etc. Ele lembra que chamou os diretores da série e observou: "Nós não queremos fazer sexo de TV. Sexo televisivo não é sexo real. Ninguém tem relações sexuais assim. E todos riam e diziam: sim, isso é verdade. Então o que você quer fazer? Eu disse: façam como se fosse real" (RYAN, 2017, tradução minha).

Essa observação é uma boa pista, mas é inevitável perguntar a Moore o que é sexo "real". Depois de afirmar que as cenas de sexo precisam estar diretamente ligadas à narrativa (evitando, assim, os clichês visuais de sempre), Moore lembra que costumava perguntar a sua equipe: "por que vamos fazer 
isso? Qual é a razão da história? Qual é a razão da personagem? Não se trata apenas de vê-los nus novamente, porque já os vimos nus antes, e eles são quentes" (RYAN, 2017).

O momento mais interessante da entrevista gira em torno do episódio 7:

Maureen Ryan - Voltando ao episódio do casamento: você escalou uma diretora e uma escritora.

Robert T. Moore - Eu pensei que seria importante. É uma noite de núpcias. Vai ter um monte de sexo nela. Eu me reuni na sala dos roteiristas com pessoas que conheciam profundamente os livros, ao lado dos que estavam lendo pela primeira vez. [...] O roteirista [deste episódio] tinha que ser alguém que realmente conhece o livro, que ama a história, porque ele escreveria algo realmente importante. Deveria ser um dos fãs de Outlander e deveria ser uma mulher. Daí partiu a escolha de Anne Kenney. [...] No meu íntimo, pensei: será uma boa maneira de evitar...

Maureen Ryan - A cortina e a vela.

Robert T. Moore - Sim. [...] Eu simplesmente sentia, por algum motivo, que uma mulher se aproximaria da cena de maneira diferente. Num outro contexto emocional, mais intuitivamente, o que causaria uma diferença visual. A cena seria mais sobre o encontro dessas duas pessoas do que um momento erótico, tentando fazê-los parecer sexy. Sem o tal "olhar sexy". Fazer a cena como as pessoas de verdade fazem sexo.

Maureen Ryan - Observando isso, percebo o quanto eu fui treinada para ver as mulheres através dos olhos dos homens, pelo menos enquanto fui uma simples espectadora. Por outro lado, [...] eu não fui treinada para ver os homens através dos olhos das mulheres. É muito raro isso acontecer. Robert T. Moore - [...] É como se houvesse uma equação: sexo é igual a mulheres. Se você vai ver algum sexo, tem que ser com mulheres. Não precisa ser o corpo inteiro. Pode ser apenas seu sapato. Pode ser qualquer parte de seu corpo. Mas não vai ser com um homem. Definimos "sensualidade" visualmente, e a imagem tem que ser de uma mulher. Vai ser sobre o corpo feminino, de alguma forma. Essa é a linguagem visual da indústria. Como chegamos a este lugar é uma outra conversa. Mas é onde estamos (RYAN, 2017).

As acusações de Laura Mulvey, na distante década de 1970, parecem estar de pé: nas cenas de sexo, as mulheres, na opinião de Moore, ainda são mostradas como objetos para o olhar voyeurístico dos homens nas produções audiovisuais. Contudo, se Moore e sua equipe parcialmente feminina decidiram enfrentar esse panorama machista, o que fizeram de concreto na cena mais "quente" de Outlander? 


\section{Os olhos de Diana Gabaldon}

Nossa análise começa com a estratégia narrativa adotada pela escritora Diana Gabaldon para moldar o caráter de sua heroína, Claire Randall. A ação principal de Outlander é a viagem no tempo de Claire. O enredo a relaciona intimamente com três homens: seu marido em 1945, Frank Randall; um antepassado de seu marido em 1743, o capitão Jack Randall; e um jovem soldado escocês em 1743, Jamie Fraser. Todos eles são personagens importantes, com seus objetivos e conflitos próprios, mas é Claire, uma mulher, que provoca as maiores reviravoltas dos romances. É também a sua voz que narra os acontecimentos - a série manteve essa estrutura incólume. Sendo a protagonista e a narradora (com uso constante de offs em primeira pessoa), Claire torna-se o centro inconteste da trama na TV.

Claire é uma sassenach, uma estrangeira, pois é uma inglesa na Escócia. Ao viajar no tempo, perdeu seus laços familiares e suas referências culturais. Em compensação, seus conhecimentos práticos de medicina (foi enfermeira na Segunda Guerra Mundial) vão ajudá-la a conquistar certa reputação como curandeira. Outra vantagem de viajar no tempo é conhecer, pelo menos superficialmente, episódios históricos, como batalhas decisivas entre ingleses e escoceses, que passam a viver no presente da narrativa. Isso a leva ao clássico paradoxo da viagem no tempo - é possível mudar o que aconteceu? - e a coloca numa posição de constante proteção do seu segredo.

No entanto, há um outro segredo, talvez ainda mais importante: Claire é casada em 1945. Quando, em 1743, ela se aproxima do escocês Jamie, solteiro e virgem, ela é, com certeza, mais experiente e mais segura do que ele quanto a relacionamentos sentimentais e ao sexo. É, portanto, uma mulher que, nos planos narrativo e dramático, não se enquadra no clichê descrito por Laura Mulvey e pela crítica feminista ao cinema. Ela não é submissa, não é um simples objeto para o desejo masculino e tem o protagonismo da ação. O roteiro de Anne Kenney para o episódio 7 da série usa todas essas características do romance para construir seu arco dramático. 
O casamento de Claire e Jamie, sem o qual não haveria cena de lua de mel, é provocado por uma questão legal. Embora os dois, nitidamente, sintam-se atraídos um pelo outro, Claire continua casada em sua memória e teria grandes dificuldades para simplesmente renegar seu compromisso com Frank e jogar-se nos braços de Jamie. Em 1743, entretanto, o malvado capitão Jack Randall poderá prendê-la a qualquer momento se ela continuar sendo uma estrangeira (inglesa) na Escócia. A solução é casá-la com um escocês solteiro, e o único disponível nas proximidades é Jamie, que aceita o encargo sem reclamar.

O seguinte diálogo do romance é uma boa síntese da situação:

- Você está a salvo - disse ele com firmeza. - Tem meu corpo e minha família, meu clã e, se necessário, a proteção de meu corpo também. O sujeito não vai colocar as mãos em você de novo enquanto eu viver. - Obrigado - falei. Olhando para aquele rosto forte, jovem, determinado, com as maçãs do rosto pronunciadas e o maxilar sólido, senti pela primeira vez que esse esquema absurdo de Dougal podia na verdade ter sido uma ideia razoável.

A proteção de meu corpo. A frase atingiu-me com um impacto particular ao olhar para ele - os ombros largos e decididos e a lembrança de sua graciosa ferocidade, "se exibindo" com a espada à luz da lua (GABALDON, 2014, p. 260).

Impossível não destacar a grande quantidade de adjetivos que Claire usa para descrever os atributos físicos de Jamie: "rosto forte, jovem, determinado"; "maxilar sólido", "ombros largos" etc. Na série, tanto Claire quanto Jamie são interpretados por artistas de grande beleza física: Caitriona Balfe (que foi modelo antes de ser atriz) e Sam Heughan (ator de teatro na Escócia antes de ser escalado em Outlander). O roteiro é construído para que o espectador anseie pela união romântica dos dois, que é ameaçada pelo desejo lascivo e violento do capitão Randall. O ator Tobias Menzies (dez anos mais velho e sem tanta beleza física) vive as duas personagens de sobrenome Randall, o que é importante na elaboração do conflito psicológico de Claire.

Um detalhe precisa ainda ser acrescentado: o corpo de Jamie, além de jovem, é cheio de músculos. No entanto, este mesmo corpo abriga uma grande 
fragilidade: as costas de Jamie estão cheias de cicatrizes vermelhas, de aspecto repugnante, resultado de um açoitamento executado pessoalmente pelo capitão Jack Randall alguns anos antes, e que quase levou o jovem escocês à morte. Jamie, assim, carrega uma marca de sua humanidade e do perigo constante que corre. Se Jack prendê-lo novamente, provavelmente será assassinado.

Aí está, em resumo, a situação das personagens quando a cena da lua de mel acontece, tanto no livro de Gabaldon, quanto no roteiro de Kenney. No romance, os acontecimentos são os seguintes:

1. Claire e Jamie tomam vinho e, ainda vestidos, de mãos dadas, têm uma longa conversa sobre a família de Jamie;

2. Jamie também conta, em linhas gerais, a história de sua vida e reafirma sua virgindade;

3. Claire inventa uma história para si, omitindo a viagem no tempo;

4. quando as histórias acabam, e eles têm de ir para a cama, Jamie ajuda Claire a tirar suas roupas;

5. Claire tira as roupas de Jamie e começa a acariciá-lo (ou seja, a iniciativa é dela);

6. Jamie acaba reagindo - "Ele me ergueu nos braços e se sentou na cama, segurando-me em seu colo" (GABALDON, 2014, p. 268) -, mas age sempre com cuidado e pede que ela o oriente, caso seja rude;

7. o primeiro intercurso não é narrado. É uma elipse clássica;

8. os dois conversam depois do sexo sobre o que aconteceu. Jamie diz estar surpreso sobre o fato da relação acontecer face a face, e não "por trás, como os cavalos" (GABALDON, 2014, p. 269). Jamie diz que seus conhecimentos de sexo vieram da observação de animais na fazenda da família e das dicas dos tios;

9. Claire faz com que os dois fiquem nus, frente a frente, e se examinem. A narradora enfileira mais meia dúzia de adjetivos para o corpo de 
Jamie (os ossos são "longos e graciosos", e os músculos são "lisos"). Excitados, partem para novo intercurso (outra vez em elipse);

10. ao sair do quarto para pegar pão, já que estão famintos, Claire é recebida por uma "retumbante ovação de uns quinze homens, descansando em volta da lareira no salão principal embaixo, bebendo, comendo e jogando dados" (GABALDON, 2014, p. 271). A alegria desses homens vem da constatação de que o casamento está consumado. Claire, constrangida, volta para o quarto;

11. Jamie vai buscar pão e vinho;

12. quando Jamie volta, acontece um terceiro intercurso, em que ela toma a liberdade de guiá-lo mais explicitamente nas ações. Ela grita de prazer, o que o assusta. Pensa que a machucou. Eles param e conversam de novo;

13. como ele "ainda está pronto", Claire parte para o sexo oral, primeiro com os lábios, suavemente, depois com os dentes, sendo mais rude. Ele atinge o orgasmo e diz: "Pensei que meu coração fosse explodir."; os dois vão dormir.

Em resumo, Claire é a protagonista e narradora das ações na cena sexual. Mais experiente, "ensina" Jamie a fazer amor, pois este tem muita energia, mas nenhuma técnica. O corpo de Jamie é objeto para os olhos e o desejo de Claire, enquanto o corpo dela não vira objeto (devido ao fato da cena acontecer sob o seu ponto de vista), ficando a subjetividade de Jamie quase ausente. Há três intercursos e um episódio de sexo oral (decidido por ela), com intervalos para longas conversas sobre vários assuntos, o que contraria frontalmente o clichê de que o homem, depois do sexo, deseja que a mulher se transforme numa pizza ou numa garrafa de cerveja. Gabaldon, de modo consciente ou não, escreveu um capítulo que oferece uma alternativa estética literária "feminina" para a narrativa erótica audiovisual machista e voyeurista descrita por Mulvey no primeiro capítulo deste ensaio. 


\section{Os olhos de Anne Kenney e Anna Foerster}

A cena correspondente no sétimo episódio da primeira temporada da série Outlander, com roteiro de Anne Kenney e direção de Anna Foerster, acontece num quarto iluminado por uma lareira e algumas velas. A ação pode ser assim resumida:

1. o casal brinda e toma vinho. Claire está tensa e bebe rápido. Jamie diz que ela deve ficar tranquila, pois não irá estuprá-la. Ela pergunta por que Jamie aceitou casar com el. Ele fala que foi para garantir a segurança de Claire²;

2. Claire aproxima-se de Jamie e senta ao seu lado na cama. As mãos se tocam, e eles vão se beijar, mas Claire pergunta sobre a família de Jamie. Segue-se uma longa conversa (indicada por fusões) sobre as duas famílias. Ela relaxa e consegue divertir-se com as histórias de Jamie;

3. dois soldados escoceses entram no quarto para saber o que estava acontecendo (episódio cômico);

4. Claire propõe que se deitem. Jamie ajuda Claire a tirar seu espartilho. Gestos lentos e iluminação discreta. Os seios de Claire são revelados. Jamie os acaricia;

5. Claire ajuda Jamie a tirar sua roupa (o kilt). Beijam-se. Jamie vira Claire de costas para ele, mas, quando caem na cama, ela fica de frente. Claire reclama que ele a está esmagando. O intercurso é rápido e, com certeza, não é prazeroso para Claire;

6. conversam sobre a experiência. Ele diz que não imaginava a relação face a face. Ela ri. Jamie pergunta se ela gostou da relação, e ela se cala. Jamie conta dos conselhos grosseiros que recebeu;

7. Claire sai do quarto à procura de comida, mas é obrigada a voltar pelos participantes da festa; 
8. Jamie vai pegar comida. Na volta diz a Claire que ouviu o seguinte conselho: "Nunca deixe uma mulher vê-lo ansioso para satisfazê-la. Isso dá muito poder a ela";

9. o casal come e bebe uísque. Jamie elogia os cabelos de Claire, numa prosa poética. Ele a acaricia, mas ela prefere falar sobre o novo kilt de Jamie;

10. cenas em flashback: (a) com Jamie e um dos outros escoceses (Murtagh), sobre o kilt. A mãe de Jamie é lembrada; (b) um padre é convencido a oficiar o casamento; (c) amigos de Jamie conseguem um anel de noivado; (d) um outro amigo de Jamie consegue um vestido de casamento para Claire;

11. cena em flashback do casamento. No final, o beijo apaixonado dos noivos;

12. de volta ao quarto, Claire pede que Jamie tire sua roupa e diz: "Quero olhar para você". Ele se aproxima dela e tira a própria roupa. Vemos as cicatrizes de suas costas. Claire acaricia o peito de Jamie, vai rodando em torno dele e acaricia suas nádegas. Jamie pede que ela também tire a roupa, o que ela faz. Vemos seus seios e seu corpo todo de costas. Eles abraçam-se e beijam-se. Jamie a ergue e a leva para a cama. Jamie começa o intercurso do mesmo modo que na relação anterior, mas dessa vez ela reage com mais entusiasmo. Depois de uma pequena conversa, Claire faz com que Jamie fique deitado de costas, enquanto ela toma a iniciativa e o morde no peito. Logo depois, começa uma ação de sexo oral (fora de quadro);

13. final da relação, com orgasmo de Jamie. Ele diz: "Pensei que meu coração fosse explodir". Ele dorme. Ela levanta, coloca um cobertor nos ombros e desce para a sala, onde pega comida e tem um diálogo tenso com um dos chefes escoceses;

14. Claire volta ao quarto. Jamie acorda e presenteia Claire com um colar de pérolas que pertencera a sua mãe. Claire o beija. Senta no colo de Jamie e começam uma nova relação, bem lenta e romântica. Fim da sequência. 
Há uma evidente semelhança de base emocional nas narrativas literária e audiovisual. As duas personagens agem de modo muito semelhante quanto ao sexo (ela mais segura, liderando as ações; ele mais tímido, aprendendo o que fazer), o que parece corroborar as palavras do showrunner Ronald D. Moore em sua entrevista à Variety. Não se trata de uma cena de sexo com a dominação física de um homem sobre uma mulher; as duas personagens têm tempo para mostrar suas subjetividades, e o desejo feminino não está subjugado ao masculino.

Uma diferença narrativa importante diz respeito à opção da série em intercalar cenas do passado recente (preparação do casamento e sua cerimônia religiosa), na forma de flashbacks, com as cenas de sexo. Isso não acontece no romance, que resolve todas as questões do casamento antes de partir para a sequência erótica. Talvez a roteirista tenha imaginado que essas pausas entre as ações mais íntimas contribuam para dar ritmo a uma sequência que ficaria demasiado longa com imagens e falas somente dos dois protagonistas. É possível que ela esteja correta. No romance, também não há pressa na descrição do sexo, que acontece em paralelo com conversas longas. Nesse sentido, o efeito geral dos flashbacks é adequado. A própria Claire, no romance, avisa que, para as mulheres, quanto mais devagar melhor.

Outra diferença está no modo mais explícito com que a série mostra o sexo. No romance, as duas primeiras relações acontecem em elipse, sendo descritas por diálogos posteriores. Na série, vemos o que está acontecendo com muito mais detalhes, inclusive quanto aos corpos das personagens. Há uma evidente preocupação em "empatar o jogo" da relação: Claire pede a nudez de Jamie, e depois Jamie pede a nudez de Claire. Não há, com certeza, o predomínio do olhar masculino sobre o corpo feminino. As nádegas de Jamie são mostradas com o mesmo destaque (talvez até com um tempo um pouco maior) que as nádegas de Claire.

No romance, há três intercursos e um episódio de sexo oral, nessa ordem. Na série, a sequência é um pouco diferente: dois intercursos, sexo oral e um 
terceiro intercurso. Assim, em vez do final ser com um orgasmo masculino (o que acontece no romance), há um clímax de prazer compartilhado, numa relação que parece ser a mais longa e carinhosa de todas. As "lições de amor" dadas por Claire, portanto, parecem ser mais exitosas na série que no livro. Se o texto de Gabaldon já aponta para o enfrentamento e a negação da representação tradicional do sexo, à procura de um ponto de vista mais feminino, o roteiro de Kenney e a direção de Foerster levam essa perspectiva ainda mais longe.

\section{Um breve último olhar}

A importante questão proposta pelo showrunner Ronald D. Moore - como a indústria audiovisual chegou ao tipo de representação (machista) do sexo nos filmes? - mereceria um ensaio específico. Ela só pode ser respondida numa articulação de componentes histórico-culturais e evolutivo-biológicos. Em outras palavras, teríamos de considerar a coevolução de genes e memes. Não há espaço aqui para nem ao menos esboçar um raciocínio nesse sentido. Fica para outra ocasião. Com base nos dados sobre a narrativa de Outlander aqui descritos, contudo, é possível fazer algumas considerações.

Se a equipe de realização de uma obra audiovisual está, de modo consciente e homogêneo, disposta a não seguir os clichês machistas das cenas de sexo (conforme descritos por Mulvey na década de 1970 e ainda tão presentes nos filmes e séries contemporâneos), ela pode fazê-lo com êxito. A cena que analisei na série Outlander é, definitivamente, mais feminina que masculina. Não há, nem de perto, a submissão da mulher ao desejo masculino. Claire nunca é um objeto para Jamie. Essa perspectiva, é claro, surge pelo fato de Gabaldon ter criado uma personagem mulher que é protagonista e narradora. Na adaptação, esse ponto fundamental da dramaturgia foi mantido.

Por outro lado, se podemos afirmar que não há predominância do olhar masculino, é preciso notar que o olhar, a visão, continua sendo, dos cinco sentidos, aquele que predomina na elaboração do erotismo. E isso acontece tanto no romance quanto na série. O texto de Gabaldon e as imagens filmadas 
por Foerster colocam o corpo de Jamie à disposição do olhar de Claire, e viceversa, ficando o espectador (e a espectadora) alternadamente com os dois pontos de vista. Assim, não há uma negação, ou uma tentativa de amenizar o componente voyeur da relação erótica. A mulher aceita ser um pouco objeto para o olhar masculino, contanto que o homem também aceite ser objeto temporário para o seu olhar. É um voyeurismo democrático e consentido, mas, ainda assim voyeurismo. Nada se escreve e nada se filma sobre odores, sabores ou texturas. Nada se escreve e nada se filma sobre os sons da paixão erótica. O lugar privilegiado do sexo ainda está no fundo da retina, de onde parte para as manobras mais decisivas nas mentes dos amantes. A nudez ainda é elemento fundamental na narrativa.

Acredito que não há qualquer problema ético nesse fato. Os corpos - nus ou vestidos - de Claire e Jamie, envolvidos numa relação erótica igualitária, sofreram na série um evidente processo de subjetivação. A acusação principal de Laura Mulvey - de que a mulher é sempre objeto do desejo masculino e oferece seu corpo sem nada receber em troca - não cabe em relação a Outlander. Quanto ao "prazer visual" da narrativa cinematográfica - que Mulvey aponta como um grave problema nas obras de diretores consagrados como Otto Preminger, Howard Hawks, Alfred Hitchcock e Josef von Sternberg - creio que é muito mais uma consequência da importância do olhar - seja masculino, seja feminino - na construção do desejo sexual (real ou representado na ficção), que uma estratégia machista consciente, embora possa reforçar, de forma inconsciente, estereótipos nocivos. Outlander mostra que uma personagem feminina também pode desejar um corpo masculino e ter prazer visual numa narrativa cinematográfica. O problema nunca foi o desejo, e sim sua privatização pelo gênero masculino. A indústria audiovisual precisa de mais mulheres escrevendo e dirigindo filmes e séries para que a representação do desejo seja mais igualitária. Creio que esse movimento, embora ainda tímido, é irreversível. 


\section{Referências}

BARKOW, J. H.; COSMIDES, L.; TOOBY, J. (Org.). The adapted mind: evolutionary psychology and the generation of culture. New York: Oxford University Press, 1992.

FREUD, S. Três ensaios sobre a teoria da sexualidade. In: FREUD, S. Obras psicológicas completas de Sigmund Freud. Rio de Janeiro: Imago, 2006. v. VII, p.119-231.

GABALDON, D. Outlander: a viajante do tempo. Rio de Janeiro: Saída de Emergência, 2014.

IMDB - Internet Movie Database. Outlander. Disponível em: <https://goo.gl/ ynYV32>. Acesso em: maio 2017.

METZ, C. Linguagem e cinema. São Paulo: Perspectiva, 1980.

MULVEY, L. Prazer visual e cinema narrativo. In: XAVIER, I. A experiência do cinema: antologia. Rio de Janeiro: Graal; Embrafilme, 1983. p. 437-453.

ROUDINESCO, E.; PLON, M.; JORGE, M. A. C.; RIBEIRO, V. Dicionário de psicanálise. Rio de Janeiro: Zahar, 1998.

RYAN, M. Showrunner Ronald D. Moore on how 'Outlander' avoids formulaic sex scenes. Variety, New York, 2016. Disponível em: <https://goo.gl/2Au4BT>. Acesso em: maio de 2017.

submetido em: 14 jun. 2017 | aprovado em: 28 jun. 2017 